\title{
MORAL E HISTÓRIA NA DOUTRINA MATERIALISTA DO BARÃO D'HOLBACH
}

\author{
Thomaz Kawauche ${ }^{1}$
}

Resumo: Este artigo pretende discutir a possibilidade de juízos deontológicos na educação moral que o Barão d'Holbach propõe em seu sistema materialista. Para tanto, os conceitos de interesse, progresso, utilidade e virtude são passados em revista do ponto de vista do ensino da história. Afirma-se aqui que a ideia de educação moral do Barão é ambígua, pois, por um lado, ela deve se mostrar coerente com a visão deontológica da "moral de interesse" (nessa perspectiva, a virtude é um dado natural e o aprendizado consiste na regulação de hábitos em conformidade à natureza), mas por outro lado, o ensino da história não deixa de ser teleológico, pois pressupõe que a ordem política livre das representações religiosas é um bem futuro cuja realização depende do esclarecimento atual dos indivíduos com base nos exemplos do passado.

Palavras-Chave: educação - história - moral - natureza - progresso.

No capítulo 11 da primeira parte do Système social, o Barão d'Holbach toma como objeto de reflexão "os verdadeiros princípios da moral". Ele inicia sua exposição rejeitando dois tipos de abordagem da moral: por um lado, descarta a hipótese da lei como convenção, segundo a qual os princípios da moral seriam arbitrários, de tal maneira que não haveria distinção natural entre virtude e vício, o que corresponderia grosso modo àquilo que, hoje, denominamos positivismo jurídico; e, por outro lado, descarta a hipótese do homem depravado, que, na esteira da doutrina moral da religião cristã, se refere à natureza humana como essencialmente desvirtuada, donde se explicaria o porquê de os homens sempre acabarem praticando o mal, a despeito da liberdade que teriam para escolherem a prática do bem.

Segundo Holbach, ambas as abordagens ignoram que, em função de sua constituição física e psicológica, o homem é movido por necessidades, as quais se expressam mediante as paixões. Ignoram ainda que, apesar de apresentarem tendências naturais a certos objetos, as paixões podem ser bem ou mal dirigidas pela educação e, assim, levar a ações consideradas - não por convenção, mas em si mesmas - viciosas ou virtuosas. Holbach preconiza um uso

${ }^{1}$ Doutor em Filosofia pela Universidade de São Paulo e Professor Visitante na Universidade Federal de São Paulo. 
das paixões conforme a natureza do indivíduo e do Estado, o que para ele significa: um controle das tendências do agente que, sem anular sua natureza, conduzam-no à virtude, levando-se em conta, evidentemente, que essa natureza e essa ideia de virtude se realizam em meio a interações sociais. Assim, embora seja natural ao homem buscar o prazer, essa busca não deve resultar em crimes ou excessos que prejudiquem os outros homens, pois antes de tudo, é preciso assegurar um convívio em sociedade que garanta o bem comum. Holbach fala, não do homem em geral, mas do homem sociável, e por isso considera as relações humanas necessárias à satisfação dos desejos particulares, tanto quanto para a realização da felicidade comum.

Situemos o problema. Trata-se de uma discussão sobre o conceito de virtude no registro da filosofia materialista do século XVIII francês. O que Holbach define como virtuosa é a disposição do homem que, pelo fato mesmo de ser movido por paixões, busca com prazer (um prazer físico, poderíamos dizer sem risco de errar) o que é útil para o Estado civil. Na medida em que o indivíduo é bem sucedido em satisfazer suas necessidades físicas em meio à - e por meio da - sociedade, ele adquire mérito perante os demais e, por isso mesmo, é considerado mais virtuoso. Lembremos da passagem correspondente, no Système de lanature, onde essa ideia é colocada: "Tal é, portanto, o verdadeiro fundamento de toda moral; o mérito e a virtude são fundados sobre a natureza do homem, sobre suas necessidades. É somente pela virtude que ele pode se tornar feliz" ${ }^{2}$.

Tal concepção de sociabilidade leva a uma ideia de virtude que se distingue tanto da virtude cristã, pois a utilidade diz respeito ao mundo presente e não ao reino dos céus, quanto da virtude dos convencionalistas, que poderíamos designar por legalistas, pois definem a ação virtuosa pela obediência às leis civis. O que fundamenta tal disposição é um certo tipo de amor de si, que Holbach, na carona de Helvétius, chama de interesse. É o que lemos noSystème social:" $\mathrm{O}$ interesse é o desejo excitado pelo objeto sobre o qual cada homem constitui seu bem-estar"; e um pouco adiante: "Para o homem de bem, interesse significa equidade, beneficência, grandeza de alma, desejo de merecer a estima dos outros, ou desejo de estar bem consigo mesmo". ${ }^{3}$

Trata-se de considerar o interesse como um princípio de ação que, naturalmente (isto é, devido à própria constituição fisiológica expressa através das paixões do agente), obriga o homem a amar a virtude e detestar o crime. O amor de si mesmo, na doutrina de Holbach, delimita, pois, uma esfera de ação no interior da qual a realização do prazer se coaduna tanto com a autopreservação quanto com os mecanismos de reforço do liame social, uma vez que torna desejável a utilidade por parte de toda uma coletividade de agentes movidos por interesses particulares. A formulação desse princípio de ação aparece no Système social como uma inclinação passional para o bem-estar comum: "Por consequência do amor que todo homem tem por si mesmo, deseja naturalmente o poder, ou seja, deseja ser capaz de influenciar o bem-estar de outros tendo em vista fazê-los contribuir para seu próprio bemestar" 4 .

${ }^{2}$ HOLBACH, Système de la nature, I, 15, p. 346.

${ }^{3} \mathrm{HOLBACH}$, Système social, I, 6, p. 60 e 63-64.

${ }^{4} \mathrm{HOLBACH}$, Système social, I, 12, p. 143. 
O modelo é claramente individualista, pois o bem-estar coletivo pressupõe o bemestar de cada um dos agentes interessados nesse pretenso acordo comum. É a chamada moral de interesse, expressa na máxima do Système de lanature: "o interesse é o único móbil das ações

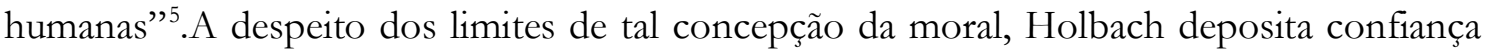
no interesse como motor do corpo político, pois parece-lhe que, no contexto do Estado, o amor de si leva naturalmente à busca de um bem comum, e não do vício nem da injustiça, o que faria da doutrina materialista da moral uma alternativa sensata às duas anteriormente mencionadas.

Evidentemente, nessa perspectiva a ignorância constitui um obstáculo para a realização da justiça no Estado. Pois a falta de conhecimentos pode fazer com que os homens confundam as ideias de bem e mal. Além disso, a ignorância leva o cidadão a buscar os fundamentos do juízo nas revelações divinas, e não em sua própria natureza e na situação social em que se encontra. Daí a importância da educação: para Holbach, é preciso que os homens ensinem-se uns aos outros a admirar certas atitudes virtuosas e a detestar todo tipo de crime sem que, para tanto, recorram a verdades sobrenaturais a fim de fundamentar a moral. A pedagogia holbachiana exclui qualquer tipo de transcendência da ética: são os próprios homens que, desejando a estima dos demais, se policiam e se impedem de cometer atos moralmente reprováveis. E isso, sem a necessidade de um deus que puna os infratores da lei, até mesmo nos casos de delitos que ocorrem secretamente, longe dos olhos do público: "a educação, guiada por interesses públicos, deveria sempre ensinar aos homens a se estimarem eles mesmos, a recear o desprezo dos outros, a temer a infâmia mais que a morte"

A educação é, portanto, responsável pela formação de uma opinião pública, um tribunal de justiça imanente à sociedade, que serve não apenas de referência para o senso moral da ordem civil, mas que funciona ainda como órgão de censura, nos moldes da instituição romana que Rousseau descreve no Contrato social (IV, 7). A disposição que propicia o domínio das paixões nocivas ao Estado civil é, portanto, uma obra de arte pedagógica, e dela depende a própria sociedade. Nesse sentido, a educação é fundamental para a moral, pois, sem o esclarecimento acerca do bem e do mal, não é possível ao homem viver em sociedade, por mais "natural" que seja a escolha pelo bem. O que está por trás desse mecanismo psicológico de deliberação que pressupõe um trabalho (entenda-se um hábito ou uma arte) que o determine diz respeito ao próprio conceito de liberdade segundo Holbach: "a faculdade de trabalhar para a própria felicidade em conformidade com a justiça"

Ora, sabe-se que o tema da educação é, desde a paideia grega, indissociável da ideia de "modelo", no sentido de paradigma ou exemplo, que as narrativas históricas apresentam para as crianças. Todavia, como veremos a seguir, o ensino da história em Holbach é problemático devido aos preconceitos do historiador que podem estar implicados até mesmo nos melhores exemplos de justiça. Daí o sentido das recomendações do Barão quanto aos critérios para se julgar as ações exemplares dos homens, tanto as que devem ser consideradas modelos de virtude nas narrativas históricas, quanto as que devem ser condenadas, também

${ }^{5} \mathrm{HOLBACH}$, Système de la nature, I, 15, p. 342.

${ }^{6} \mathrm{HOLBACH}$, Le Christianisme dévoilé, XVI, p. 289.

${ }^{7} \mathrm{HOLBACH}$, Système social, I, 10, p. 107. 
exemplarmente, junto com todos os vícios que destroem o Estado civil. Deve-se, segundo ele, rejeitar nas histórias os costumes dos bárbaros, as opiniões dos supersticiosos e, até mesmo, as doutrinas de certos filósofos quando estas se apoiam em preconceitos.

A educação, assim compreendida, depende ao mesmo tempo do conhecimento da história e de sua crítica. Ora, o que temos aí de novidade? Pois, até esse ponto, não há nada de original em relação aos antecessores do Barão. A própria história da filosofia está repleta de críticos das tradições e dos costumes. Os exemplos seriam infindáveis e a lista incluiria até mesmo autores que Holbach detestava, como Platão. Precisemos, então, a análise.

O que Holbach deseja é tão-somente uma verdade estabelecida pela razão e pela experiência do próprio indivíduo.; ou, se pensarmos no contexto do século XVIII europeu, uma certa atitude com implicações cognitivas e morais que, por exemplo, Rousseau na Profissão de fé do vigário de Saboia relaciona à "consciência", e que Kant abordará na Fundamentação da metafísica dos costumes mediante o conceito de "autonomia". Todavia, Holbach realiza tal projeto pedagógico, não mediante uma censura da história (como Platão, que na República exclui das narrativas poéticas os maus exemplos), mas com a rejeição sumária do ensino da história, como se não houvesse conciliação possível entre o conhecimento histórico e o ideal de juízo autônomo da razão. É o que Holbach parece sugerir quando diz que os historiadores "quase sempre pintam os crimes com cores sedutoras". Como compreender tal radicalismo aparentemente descabido? Leiamos a seguinte passagem do Système social:

Para julgar com sanidade as ações dos homens, para saber se elas devem ser nomeadas virtudes ou vícios, não nos reportemos a histórias, que quase sempre pintam o crime com cores sedutoras, nem a usos estabelecidos pela inexperiência e pela barbárie dos povos, nem a opiniões introduzidas e mantidas pela superstição e pela tirania, nem mesmo a filosofias que nem sempre são isentas de preconceitos. Consultemos o valor intrínseco e real das ações e das coisas; examinemos sua influência próxima ou distante acerca da felicidade dos indivíduos e das sociedades. $[. . .]^{8}$

Que haja em Holbach uma rejeição do ensino da história na formação moral das crianças, isso não deve nos surpreender no estudo da filosofia do Iluminismo. Rousseau mesmo, no Emílio, não via com bons olhos o ensino da história. Porém, como sabemos, tal censura limitava-se aos historiadores modernos, os quais só sabiam descrever os costumes corrompidos das sociedades existentes. Isso quando não explicavam os fatos humanos de um ponto de vista providencialista, como se a história fosse o terreno da intervenção divina. Rousseau aceitava em seu projeto pedagógico somente os livros dos historiadores antigos gregos e latinos -, pois estes inculcavam nos jovens leitores o espírito cívico a partir dos exemplos de virtude dos cidadãos da pólis sem se deterem nos vícios das sociedades modernas e sem se perderem em alegorias teológicas ou em interpretações inspiradas nas Escrituras.

${ }^{8}$ HOLBACH, Système social, I, 11, p. 121. 
Holbach é mais radical e rejeita até mesmo a história antiga. Em lugar dos livros dos historiadores, ele recomenda um exercício do juízo do tipo "deontológico". Para saber se as ações são virtuosas ou viciosas, não devemos consultar a história, mas examinar "o valor intrínseco e real das ações e das coisas". Ora, isso nos coloca uma dificuldade, que pode ser descrita da seguinte maneira. O princípio utilitarista que comanda a própria formação da sociedade pressupõe uma razão que seja esclarecida o suficiente para ser capaz de calcular as vantagens de se buscar uma felicidade geral para todos os cidadãos, em vez da satisfação imediata dos prazeres individuais. Daí que, uma doutrina moral posta nesses termos utilitaristas nos parece, de um ponto de vista pragmático, "teleológica": uma ação é boa ou má, não em si mesma, mas em função do bem que pode promover para o Estado civil. Lembremos que a utilidade é o princípio fundamental do juízo, no sentido de garantir o raciocínio segundo o qual cada um buscará a própria felicidade na felicidade da vida em comum, porque o útil é o útil no Estado: "A utilidade, como já disse em outro lugar, deve ser a única medida dos juízos do homem. Ser útil é contribuir para a felicidade dos semelhantes $[\ldots . .$. "'?

Evidentemente, o utilitarismo (se nos permitirmos usar um termo anacrônico para comentar esse texto) de Holbach apresenta uma dimensão teleológica. Afinal, se retomarmos a parte inicial do Système de lanature, vamos nos lembrar que as próprias paixões não são, para Holbach, nem boas nem más em si mesmas, mas podem se tornar, por intermédio da educação, boas ou más para a sociedade. É a essa conclusão que podemos chegar mediante um exame de textos como Christianismedévoilé ou Contagionsacrée, nos quais Holbach expõe sua genealogia da moral cristã. Nesses escritos, lemos que o homem não é supersticioso nem escravo por natureza, mas que é educado para se tornar assim: "ele espera sua felicidade nas quimeras porque seu governo quase sempre lhe recusou realidades" ${ }^{\prime 1}$. E recomenda uma formação moral e política calcada na concretude das coisas presentes, isto é, nas "relações sensíveis", para usarmos uma expressão dele.

O Barão d'Holbach é muito claro ao afirmar que a "natureza" supersticiosa do povo não é um dado, mas uma construção social, que tem nos maus governantes a causa, e que pode ser corrigida pela boa educação amparada por um governo justo. Em sua investigação da origem da superstição, Holbach identifica como verdadeira causa da superstição não uma natureza religiosa do ser humano, mas uma paixão contrária à natureza - o medo -, e coloca o esclarecimento como solução para essa condição: "O homem só é supersticioso porque ele é medroso; ele só tem medo porque é ignorante" ${ }^{11}$. Daí a função do pedagogo como curador do medo, como uma espécie de médico social que aplica um remédio (uma boa educação acompanhada de boas leis) para esclarecer o povo: "é preciso dar-lhe [ao povo] uma educação e leis que os convidem, os habituem e os obriguem a viver de uma maneira verdadeiramente conforme à natureza" 12 .

É preciso observar que, no sistema da natureza holbachiano, as coisas existem por necessidade, pois há um determinismo físico, até mesmo no campo da moral, de modo que a razão calculadora, que pondera e escolhe aquilo que é mais útil, não é livre para escolher

\footnotetext{
${ }^{9}$ HOLBACH, Système de la nature, I, 15, p. 338.

${ }^{10}$ HOLBACH, Le Christianisme dévoilé, XVI, p. 291.

${ }^{11}$ HOLBACH, La Contagion sacrée, I, p. 1.

${ }^{12}$ HOLBACH, La Contagion sacrée, I, p. 20.
} 
entre o útil e o inútil. A liberdade, na doutrina materialista de Holbach, diz respeito ao esclarecimento de decidir segundo a necessidade da natureza, o que no caso da moral significa optar pelo caminho que naturalmente deve ser seguido, ou seja, o da maior utilidade. Escolher o vício seria algo contrário à natureza, e somente um homem irrazoável ou mal educado é que poderia errar agindo assim. O esclarecimento mostra à razão o caminho correto, e o interesse do homem esclarecido vai nessa direção, naturalmente, ou, dito de outra forma, pelo hábito adquirido para fazer sempre escolhas nessa direção: “Qual é o objeto da moral senão o de mostrar aos homens que seu interesse exige que reprimam suas paixões momentâneas em vista de um bem-estar mais durável e mais verdadeiro que aquele que proporcionaria a satisfação passageira de seus desejos?" ${ }^{13}$.

Daí se compreende o fato de Holbach rejeitar tanto os convencionalistas, que não discernem o bem ou o mal em si mesmos, quanto os pessimistas, que veem como realidade apenas o mal em si mesmo. A teleologia no raciocínio ético de Holbach visa a um bem em si mesmo, um bem natural, que é confirmado pelo cálculo da razão, e que determina a própria ação do homem razoável, pois ele não poderia escolher aquilo que, em sua essência, não fosse um bem em si mesmo. A noção de progresso implicada na concepção materialista da moral em Holbach não diz respeito a um movimento do espírito rumo a um estado de maior perfeição do ser humano, como será em Hegel por exemplo, e sim a um movimento necessário da configuração fisiológica do indivíduo, ou ainda, um rearranjo interno de suas partes constitutivas e de sua dinâmica de funcionamento, numa tendência natural (isto é, mecânica) para o equilíbrio das necessidades do organismo ao longo do tempo em função dos estímulos externos.

Por esse motivo, não nos parece adequado tentarmos classificar a ética holbachiana nos termos benthaminianos (abordagem anacrônica, portanto) de deontologia ou teleologia: há, certamente, um utilitarismo que nos levaria a pensar numa teleologia, porém, há também um determinismo materialista que, quando traduzido para o vocabulário da moral do sistema de Holbach, essencializa ou, pelo menos, relativiza o caráter teleológico das ações interessadas, permitindo que o agente se refira a elas como boas ou más em si mesmas. Tal hipótese não parece absurda se observarmos bem a frase final da estranha passagem do Système social aqui analisada, que parece resumir nossas considerações: "examinemos sua influência próxima ou distante acerca da felicidade dos indivíduos e das sociedades". De todo modo, o que vale notar é que essa discussão sobre interesse e liberdade abre o espaço para refletirmos sobre a visão da história em Holbach. Neste ponto, há considerações que merecem ser feitas com base num artigo recente sobre a noção de história em Holbach.

Após examinar a Histoire naturelle de lasuperstition, a professora Maria das Graças de Souza descreve a visão da história em Holbach em termos metafóricos, sugerindo algo como uma cena congelada, isto é, uma imagem que se repete ao longo da projeção de uma película cinematográfica. Nessa espécie de instantâneo do movimento na história dos povos, a narrativa corresponde ao retrato de um único fato, a saber, que os padres tentam continuamente, desde a origem da sociedade até o presente, usurpar o poder dos reis. É como se, para Holbach, o movimento da história fosse uma eterna reapresentação de uma mesma fotografia tirada da situação presente, quando se assiste à impostura dos padres que

${ }^{13}$ HOLBACH, Système de la nature, I, 11, p. 234. 
enganam o povo ignorante, ao mesmo tempo que há um movimento de ordem psicológica, também contínuo e repetitivo, segundo o qual o povo se ilude com as falsas promessas da religião.

Assim, o que temos em Holbach é uma visão da história segundo a qual o gênero humano, desde os inícios, sofre a influência nefasta da religião e dos poderes sacerdotais. Tudo se passa como se não houvesse movimento histórico real, ou, em outras palavras, a história do gênero humano aparece para Holbach como a cena contínua do peso do braço sacerdotal sobre os governantes e os povos. ${ }^{14}$

Em suma, trata-se de um movimento que se realiza no campo do necessário, sem nenhuma abertura para o contingente, de modo que o conhecimento advindo da história em Holbach não oferece nada de novo, uma vez que todos os fatos, até mesmo os fatos futuros, são, de certa forma, pré-determinados e, por conseguinte, conhecidos de antemão. É um falso movimento, poderíamos dizer, pois, a rigor, os fatos não se desdobram ao longo do tempo, não há um devir histórico propriamente dito, e os agentes que protagonizam a narrativa não mudam no sentido de transformarem-se no âmago do ser, de tal maneira que, em última instância, a realidade concreta compreendida por essa "história" permanece estática.

O que se conclui dessa análise é que, na doutrina materialista holbachiana, os conhecimentos históricos são inadequados para se pensar, em relação à realidade passada e presente, um novo Estado, isto é, uma sociedade livre da religião. A história, segundo Holbach, serve apenas para mostrar como, desde a origem do Estado, a religião enganou e corrompeu os homens. É uma "cena contínua", sem "movimento histórico real", para utilizarmos as palavras de Maria das Graças de Souza.

Tal constatação, no entanto, não significa que Holbach mereceria ser excluído do rol de pensadores que compõem a ideologia do Iluminismo. Ao contrário, sua concepção de formação moral por intermédio da educação é, a rigor, claramente consonante com os discursos sobre a educação de Rousseau (Emílio) e de Kant (Resposta à pergunta: o que é Esclarecimento?). Pois, de acordo com Holbach, um exame bem refletido da marcha da história serve para mostrar ao homem razoável que a sociedade permanecerá na miséria (na "minoridade", diria Kant) enquanto os homens não buscarem o esclarecimento e a independência em relação aos impostores e aos tiranos, que desde sempre têm se valido da religião para dominar o povo. Como explica Maria das Graças de Souza no artigo citado, trata-se de uma concepção de mudança histórica conforme à perspectiva iluminista, pois, se pensarmos indutivamente com base nos fatos passados e na concepção de razão do Système de lanature, "a felicidade do gênero humano depende da descoberta progressiva da verdade, que o libertará dos poderes despóticos, cuja autoridade, desde as origens, se funda nas representações religiosas" ${ }^{\prime 15}$. Em suma, pode-se afirmar que Holbach é iluminista no sentido forte do termo porque ele antecipa, com base num raciocínio sobre a história e na crítica à

14 SOUZA, "Materialismo e história: o caso do Barão d'Holbach”, p. 35.

15 SOUZA, "Materialismo e história: o caso do Barão d'Holbach”, p. 36. 
superstição, uma melhora da sociedade pelo combate à ignorância mediante a confiança na liberdade associada à razão, muito embora suas definições de liberdade e razão sejam próprias do quadro conceitual da doutrina materialista.

Todavia, a história considerada enquanto ciência não serve para produzir tal emancipação dos homens. Porque a sociedade justa e ordenada segundo a "moral verdadeira" de Holbach só poderia ser pensada com base num conhecimento absolutamente novo, capaz de romper com a dominação ideológica da Igreja, coisa que, de acordo com a doutrina materialista apresentada em obras como o Système de lanature, não poderia vir das narrativas históricas. Estas, segundo Holbach, apenas repetem os conhecimentos do passado e até mesmo reforçam o status quo, mostrando-se portanto incapazes de mudar de modo efetivo a determinação das coisas presentes: em particular, o exame da história da religião cristã mostra apenas que ela é "nociva à felicidade do Estado, inimiga dos progressos do espírito humano, oposta à sã moral, cujos interesses da política não podem se separar jamais" "16. A ciência, entendida como saber responsável pelo esclarecimento do gênero humano, não deve nada à história. Ora, de que tipo de saber estamos falando então?

Parece-nos, com base nessas considerações, que Holbach não se contenta com uma mera reforma na educação, pois a educação depende do governo e os governantes encontram-se corrompidos pela influência nociva da religião. Educação e governo dependem um do outro, da mesma forma que se corrompem um ao outro. Assim, Holbach estaria sugerindo - hipótese que não merece ser desprezada - que a única solução seria fazer tábula rasa do mundo da cultura e começar tudo de novo, como uma nova história, porém, sem a religião para desvirtuar o homem de seu caminho natural. O Barão d'Holbach seria assim, não apenas um renovador, mas também um revolucionário, e mais ainda, com elementos de um materialismo histórico pré-marxista que, apesar de rudimentares, levariam teoricamente a um estado de reviravolta social. Estaríamos diante de um paradoxo? Um revolucionário originário da aristocracia nobiliária do Antigo Regime? Talvez, e isso, com respaldo textual. Poderíamos citar trechos que supostamente comprovam uma antecipação daquilo que lemos no prefácio à Crítica da economia-política de Marx. ${ }^{17}$ Por exemplo, na seguinte passagem de Contagion sacrée:

${ }^{16}$ HOLBACH, Le Christianisme dévoilé, p. xxvii.

17 “[...] A conclusão geral a que cheguei e que, uma vez adquirida, serviu de fio condutor dos meus estudos, pode formular-se resumidamente assim: na produção social da sua existência, os homens estabelecem relações determinadas, necessárias, independentes da sua vontade, relações de produção que correspondem a um determinado grau de desenvolvimento das forças produtivas materiais. $\mathrm{O}$ conjunto destas relações de produção constitui a estrutura econômica da sociedade, a base concreta sobre a qual se eleva uma superestrutura jurídica e política e à qual correspondem determinadas formas de consciência social, política e intelectual em geral. Não é a consciência dos homens que determina o seu ser; é o seu ser social que, inversamente, determina a sua consciência. Em certo estágio de desenvolvimento, as forças produtivas materiais da sociedade entram em contradição com as relações de produção existentes ou, o que é a sua expressão jurídica, com as relações de propriedade no seio das quais se tinham movido até então. De formas de desenvolvimento das forças produtivas, estas relações transformam-se no seu entrave. Surge então uma época de revolução social. A transformação da base econômica altera, mais ou menos rapidamente, toda a imensa superestrutura. [...]” (MARX, Contribuição à crítica da economia política, p. 23). 
Querer corrigir os costumes dos homens e torná-los mais sábios sem mudar seus governantes é um projeto impossível; esses governantes depravados se sustentam sobre as noções que a religião alimenta e cuida na infância, que o hábito enraiza nos espíritos, que o exemplo confirma e fortifica, que o preconceito torna sagrado e inviolável, e que a violência apoia e torna necessários. É preciso, portanto, desenganar os homens de seus erros religiosos, que influem sobre a política de uma maneira tão marcada, se queremos conduzi-los à felicidade. ${ }^{18}$

Um pouco antes, Holbach havia se referido ao povo revoltado por conta dos males impostos pelos padres: "um povo supersticioso, enfurecido pelo excesso de seus males, torna-se sempre um animal feroz, que, à voz de um padre fanático, está pronto para se lançar sobre o condutor rigoroso que o encarcera" ${ }^{19}$. Passagens desse tipo encontraríamos muitas, se nosso propósito fosse rotular o Barão como precursor de Marx. Contudo, é preciso distinguir a filosofia materialista propriamente dita da mera militância ateia no texto.

Tentemos, pois, escapar dos exageros retóricos dos escritos em questão notando que o materialismo de Holbach apresenta diferenças essenciais em relação ao de Marx. A primeira delas é que o materialismo holbachiano não é propriamente histórico. É preciso observar que a moral segundo Holbach é algo dado, natural, que não se constrói dialeticamente com base nas condições concretas da realidade empírica. Pois, apesar de o homem passar por estágios e suas faculdades intelectuais progredirem, ainda assim a moral é, em última instância, algo ligado à própria da natureza do indivíduo, física e psicologicamente falando, muito embora exista, de fato, uma dimensão contingente em seu percurso associada ao risco do desvirtuamento da moral pela religião. Outra diferença em relação a Marx é que, em Holbach, não há luta de classes, pois não há uma explicitação de nenhum processo por meio do qual os ricos se tornam ricos e os pobres se tornam pobres, como se a hierarquia socioeconômica fosse dada, naturalmente, sem transformações prévias. Toda a discussão permanece no plano ideológico e, diferentemente do materialismo histórico segundo Marx, a doutrina holbachiana não apresenta vínculo entre a "consciência" e as contradições concretas relativas às forças produtivas da economia responsáveis tanto pelas transformações contínuas da sociedade quanto pela produção da própria consciência individual.

Ou seja, a visão que Holbach tem da sociedade é de uma estrutura estática, e não em "luta de classes", como em Marx. A história em Marx é, como sabemos, um processo constituído por contradições internas crescentes entre interesses distintos de classes sociais em conflito constante, o qual termina numa reviravolta social que muda, de modo abruto, as relações mesmas entre os homens e, por conseguinte, a estrutura social dos meios de produção. Tal análise do funcionamento do corpo político baseado na economia é bastante - para não dizermos totalmente - estranha aos escritos de Holbach. Isso posto, não podemos ter dúvidas do conservadorismo político do Barão, que se mostra, nesses termos, um

18 HOLBACH, La Contagionsacrée, I, 7, p. 134-135.

${ }^{19}$ HOLBACH, La Contagionsacrée, I, 6, p. 130-131. 
pensador bastante contextualizado em seu tempo, isto é, comprometido com as categorias conceituais da ideologia do Antigo Regime.

Segundo essa abordagem da obra de Holbach, diríamos que esse pensador tem uma visão ambígua da moral, ao mesmo tempo histórica e ahistórica, quando conceitua o útil e seu correlato, o interesse. Pois, por um lado, em escritos como o Système de lanatureou o Système social, podemos afirmar, paradoxalmente, que a moral se constitui historicamente e que é natural. De fato, é verdade que Holbach valoriza a experiência, a ponto de dizer que ela constitui a razão de modo progressivo: o Barão realmente dá a entender, em vários escritos, que existe um progresso da razão por meio da educação. Mas, por outro lado, é preciso reconhecer que não se trata da experiência com base na história, pois a história pode, no máximo, mostrar exemplos de virtude, mas não produzir virtude de fato, o que nos desautoriza a falarmos num progresso da moral. A moral é o que deve ser, ou não é. O que produz a virtude é o hábito, isto é, a prática da virtude, mas a virtude preexiste à prática das ações virtuosas, pois ela está determinada, de antemão, na ordem e no funcionamento da própria sociedade e, em última instância, na constituição psico-fisiológica do próprio indivíduo. Trata-se de uma concepção de história peculiar, voltada para as exigências de adequação ao quadro conceitual da doutrina materialista.

Tudo se passa como se, desde o início de nossa socialização, já fôssemos virtuosos em potência, e que, por intermédio da educação, nossa razão se esclarecesse para podermos, em ato, realizarmos a nossa natureza virtuosa, tanto do ponto de vista psicológico (pois tudo começa com uma disposição das paixões para a prática do bem) quanto do ponto de vista social (quando a disposição se torna causa de atos concretos de virtude). E mesmo que Holbach fale que originalmente não somos nem bons nem maus, a natureza do Estado civil determina a realização do ser humano mediante a realização de atos virtuosos. Para evitarmos as complicações de uma investigação que especulasse acerca de uma possível "metafísica" no pensamento de Holbach - o que seria desnecessário pelo fato de a obra mesma de Holbach não autorizar uma investigação desse tipo -, digamos apenas que o que se pode concluir da "historiografia" holbachiana nos textos de moral e de crítica à religião é que o fracasso na realização da virtude em sociedade dar-se-ia eminentemente por conta da intervenção da religião, que é contrária à natureza do homem pelo fato de iludi-lo com quimeras, de modo a atravancar o progresso das coisas.

\section{MORALS AND HISTORY IN THE MATERIALIST DOCTRINE OF BARON D'HOLBACH}

Abstract: This paper aims to discuss the possibility of deontological judgments in moral education that Baron d'Holbach proposes in his materialistic system. To this task, the concepts of interest, progress, utility and virtue are reviewed from the point of view of history teaching. It is stated here that the Baron's idea of moral education is ambiguous because, on the one hand, it must be consistent with "morals of interest" deontological vision (in this perspective, virtue is a natural fact and learning consists in habits regulation according with nature), but on the other hand, history teaching is still teleological, since it presupposes that the political order without religious representations is a future good whose realization depends on the current elucidation of individuals based on the examples from past.

Keywords: education - history - morals - nature - progress. 


\section{REFERÊNCIAS BIBLIOGRÁFICAS}

HOLBACH, Paul-Henri Thiry, Baron d'. Le Christianisme dévoilé, ou Examen des principes et des effets de la religion chrétienne. Londres, 1766.

La Contagion sacrée, ou Histoire naturelle de la superstition. Londres, 1768.

Système de la nature, ou Des Loix du monde physique et du monde moral [1770]. Londres, 1771.

Système social, ou Principes naturels de la morale et de la politique, avec un examen de l'influence du gouvernement sur les mœurs. Londres, 1773.

MARX, Karl. Contribuição à crítica da economia política. São Paulo: Martins Fontes, 1997.

SOUZA, Maria das Graças de. "Materialismo e história: o caso do Barão d'Holbach". Dois Pontos, Curitiba, v. 8, n. 1, 2013. 